\title{
Políticas lingüísticas en Colombia: tensiones entre políticas para lenguas mayoritarias y lenguas minoritarias
}

\author{
Javier García León y David García León* \\ Universidad Nacional de Colombia
}

\begin{abstract}
Resumen
El presente artículo tiene como propósito analizar las actuales políticas lingüísticas colombianas, y examinar hasta qué punto se puede hablar de la promoción del bilingüismo en el país. Se sostendrá que aunque existe una política definida en torno al bilingüismo castellanoinglés, ésta no ha sido exitosa y ha generado una serie de tensiones negativas hacia la situación de bilingüismo en lenguas minoritarias. Esta hipótesis se sustenta en cuatro aspectos centrales. Primero, en el hecho de que algunos documentos oficiales asumen el bilingüismo desde una perspectiva reduccionista negando la variedad lingüística del país. Segundo, las políticas para lenguas mayoritarias generan un fenómeno de estratificación que se opone al reconocimiento igualitario de lenguas mayoritarias y minoritarias. En tercer lugar, las políticas lingüísticas generan un fenómeno de mercantilización de la enseñanza de lenguas. Por último, a raíz de dichas políticas surge un fenómeno de desconexión entre los tipos de educación bilingüe
\end{abstract}

* Para correspondencia dirigirse a: Javier García León (jaegarciale@unal.edu.co) o David García León (dalgarciale@unal.edu.co), Departamento de Lingüística, Facultad de Ciencias Humanas, Universidad Nacional de Colombia, Sede Bogotá, Edificio 214, Carrera 45, $\mathrm{N}^{\circ}$ 26-85, Bogotá, Colombia. 
que se desarrollan para lenguas mayoritarias y lenguas minoritarias. Para llegar a dicho análisis, se llevó a cabo una lectura crítica de las políticas lingüísticas colombianas. Además, las tensiones propuestas son aplicadas al caso del criollo sanandresano, lengua minoritaria del país. El artículo finaliza afirmando que en Colombia no es posible hablar de un programa nacional de bilingüismo, sino más bien de la promoción del inglés como lengua extranjera; hecho que desconoce la situación de contacto de lenguas en Colombia, especialmente el contacto entre inglés criollo y castellano.

Palabras clave: políticas lingüísticas, lenguas minoritarias, enseñanza del inglés, educación bilingüe, criollo sanandresano.

LINGUISTIC POLICIES IN COLOMBIA: TENSIONS BETWEEN POLICIES FOR MAJORITY AND MINORITY LANGUAGES

Abstract

This paper seeks to analyze current Colombian linguistic policies and examine the extent to which the proclamation of bilingualism in the country can be declared. Although a clear and marked policy on English-Spanish bilingualism exists, it can be argued that it has not successfully achieved its goals. It can also be argued that it has generated negative tensions with regard to the situation of bilingualism in minority languages. This hypothesis is supported by four central arguments. Firstly, by the fact that some official documents look at bilingualism from a reductionist perspective, ignoring the linguistic variety of the country. Secondly, policies for majority languages generate a classification phenomenon, which is opposed to the concept of equal recognition of minority languages. Thirdly, linguistic policies generate a phenomenon in which a marketization of language teaching is produced. Finally, from the root of the said policies, comes a phenomenon of disconnection between the types of bilingual education that are developed for majority and minority languages. To arrive at the stated hypothesis, a critical reading of the Colombian linguistic policies was done. Furthermore, the problems posed by this situation are exemplified with the San Andres Creole, the minority language of the country. The article ends by affirming that in Colombia it is not possible to speak about a National Bilingual Programme, but rather of the promotion of English as a foreign language. This promotion does not consider the situation of language contact in the country, especially the contact between English Creole and Spanish. 
Key words: Language policies, minority languages, English teaching, bilingual education, Islander Creole.

Recibido: 07/06/2012 Aceptado: 10/10/2012

\section{INTRODUCCIÓN}

En las situaciones de contacto lingüístico, la coexistencia de lenguas en un mismo territorio es en ocasiones conflictiva. Muchas veces el Estado se ve obligado a regular dicha relación implantando políticas lingüísticas. En el caso colombiano, la diversidad de lenguas ha conducido a la creación de dos tipos de políticas lingüísticas (de Mejía 2005). El primer grupo tiene por objetivo regular el contacto entre las lenguas minoritarias, indígenas y criollas, con el castellano, la lengua mayoritaria del país. El segundo grupo, por su parte, va encaminado a la implementación de programas de educación bilingüe para hablantes de lenguas mayoritarias a través de la inserción de una o diversas lenguas extranjeras. Aunque el propósito de cada grupo de políticas es claro, es necesario determinar cómo dichos grupos se interrelacionan y generan tensiones entre sí. Existe una amplia literatura que analiza la relación entre dichas políticas (de Mejía y Helot 2008; González 2010; Aguirre Licht 2009); sin embargo, los efectos negativos que las políticas de lenguas mayoritarias tienen en la situación de la lenguas minoritarias no se ha hecho tan evidente. De este modo, el presente artículo tiene como propósito analizar las actuales políticas lingüísticas colombianas, y examinar hasta qué punto se puede hablar de la promoción del bilingüismo en el país. Se sostendrá que aunque existe una política definida en torno al bilingüismo castellanoinglés, ésta no ha sido exitosa y ha generado una serie de tensiones negativas hacia la situación de bilingüismo en lenguas minoritarias, especialmente en el caso del contacto entre el castellano y el inglés criollo presente en las islas de San Andrés, Providencia y Santa Catalina.

Para alcanzar dicho propósito, el presente artículo se estructura de la siguiente manera. Primero, se presenta una breve descripción de la situación sociolingüística de Colombia. Luego, se hará un recorrido histórico por las políticas lingüísticas más importantes del país, clasificadas en políticas para grupos mayoritarios y políticas para grupos minoritarios. Inmediatamente después, se presentan las tensiones que han generado unas políticas y modalidades de educación sobre otras. Para ello, se tendrán en cuenta diversas investigaciones y reflexiones sobre la pertinencia de las actuales 
políticas lingüísticas. Por último, se ejemplificarán dichas tensiones con el caso del criollo inglés de San Andrés y Providencia, haciendo especial énfasis en algunos programas de educación bilingüe que se han propuesto para esta lengua. El artículo finaliza afirmando que en Colombia no es posible hablar de un programa nacional de bilingüismo, sino más bien de la promoción del inglés como lengua extranjera; hecho que desconoce la situación de contacto de lenguas en Colombia, especialmente el contacto entre inglés criollo y castellano.

\section{PANORAMA SOCIOLINGÜÍSTICO COLOMBIANO}

La situación lingüística colombiana se caracteriza por la existencia de una lengua dominante, el castellano, hablado por cerca del $98 \%$ de la población, y por el uso de más de 60 lenguas indígenas y 2 lenguas criollas. El castellano es lengua oficial y dominante en Colombia; además, se considera que la mayoría de hablantes de esta lengua no maneja las lenguas restantes y, en algunos casos, las concibe como inferiores (Gröll 2009). Aunque el castellano es la lengua mayoritaria, esto no significa que no existan ciertas diferencias dialectales. Para autores como Gröll (2009), es posible clasificar la variedad del castellano en dos grandes grupos: el español costeño, que incluye las variedades habladas en la costa atlántica y pacífica, y un grupo que, a grandes rasgos, podría denominarse español andino. Sin embargo, es necesario tener en cuenta que existen otras variedades como el castellano hablado en la región amazónica que se encuentra en contacto con un gran número de lenguas indígenas y con una lengua mayoritaria, el portugués. De esta manera, es posible afirmar que, aunque el castellano es la lengua mayoritaria, éste se caracteriza por su gran variedad dialectal y el constante contacto con lenguas minoritarias.

En cuanto a las lenguas indígenas, solo un $2 \%$ de la población colombiana las habla. Dado que existen más de 60, algunas de ellas son utilizadas como lenguas francas entre miembros de diferentes grupos indígenas que conviven en una misma región. En los territorios donde son utilizadas, sus funciones le limitan más al campo de la esfera privada, la familia, dado que el castellano ocupa la esfera pública. Por otra parte, la mayoría de ellas se clasifican en 13 familias lingüísticas: Chibchas, Arawak, Caribe, Quechua, Bora, Peba-yagua, Tupí-Guaraní, Uitoto, Tucano, Guahibo oriental y occidental, Makú-Puinabe, Sáliba, y Choco (Ardila 2012). El primer grupo es hablado, sobre todo, en la Sierra Nevada de Santa Marta, mientras que las lenguas de la familia Arawak se distribuyen a lo largo de la región del Orinoco y el río Vaupés. La familia Caribe posee hablantes tanto en el norte del Santander como en 
el departamento del Caquetá. Las lenguas agrupadas en la familia Quechua son habladas al sur del país. Por su parte, las lenguas Tucano occidental, que agrupan 15 variedades, se encuentran, mayoritariamente, en el oriente del país y muy pocas en el suroeste (M. González 2010). La familia Guahibo es hablada en Llanos Orientales, al igual que las lenguas de la familia MakúPuniabe. Dispersos en la Amazonía se encuentran los hablantes de la familia Uitoto. Por último, la familia Choco, que incluye dos lenguas, se encuentra a lo largo de la costa pacífica (Gröll 2009). Cabe mencionar que existen siete lenguas que no han sido clasificadas en familias lingüísticas: andoque, awa-cuaquier, kamsá, cotán, guambiano, nasayuwe y ticuna.

En relación con la vitalidad lingüística de las lenguas indígenas, estas son habladas por grupos muy reducidos, pues se encuentran en la mayoría entre el rango de 500 a 1000 hablantes, luego entre 100 y 500 y, finalmente, de 1000 a 5000 (Ardila 2012). De acuerdo con un estudio realizado por la Universidad Nacional de Colombia, cuyo objetivo era analizar el grado de vitalidad de las lenguas en el Amazonas, es posible afirmar que debido al contacto que dichas lenguas tienen con el castellano, éstas se encuentran en un proceso de pérdida de dominios, pues el castellano, cada vez más, pasa a ser la lengua materna de las nuevas generaciones (Ardila 2007). A la par, factores como los medios de comunicación, el contacto con instituciones occidentales y los procesos educativos han contribuido al incremento de un conocimiento pasivo de las lenguas indígenas por parte de los hablantes jóvenes. Por último, aunque es difícil elaborar diagnósticos precisos sobre la vitalidad de las lenguas aborígenes dada su gran diversidad, existen dos tendencias, según Ardila (2010): primero, hay una disminución del número de hablantes en las generaciones jóvenes y, por otro lado, se prefiere el uso del castellano, llegando incluso al ámbito familiar, hecho que podría afectar la transmisión de dichas lenguas a futuras generaciones.

Por su parte, en Colombia existen dos lenguas criollas de diferente base léxica: el palenque, de base léxica española, y el criollo sanandresano de base léxica inglesa. Estas son habladas por unos pocos miles de hablantes quienes, en la mayoría de los casos, son bilingües. Las lenguas criollas colombianas se ubican en la región Caribe y hacen parte histórica y lingüísticamente de un grupo mayoritario de lenguas que se desarrolló en dicha región, debido a procesos de conquista y colonización entre los siglos XVI al XX. En la actualidad, se presenta una situación de diglosia entre el criollo palenquero y el castellano. Sin embargo, cada vez más la lengua mayoritaria está asumiendo las funciones del criollo, generando que los jóvenes tengan un bilingüismo pasivo en dicho código. De esta manera, son los adultos y los ancianos los que, casi de manera exclusiva, utilizan la lengua (Ardila 2012). 
En el caso de de San Andrés, Providencia y Santa Catalina, se presenta una situación de trilingüismo, en la que el criollo convive con el castellano y el inglés estándar caribeño. Dicho contacto ha llevado, según Sanmiguel (2007), a un uso diferenciado de las lenguas, es decir, diglosia. De esta manera, en las islas el castellano es la lengua del gobierno y la educación, mientras que el criollo es usado en situaciones informales y cotidianas; por su parte, el inglés estándar tiene un uso marcadamente restringido, pues es solamente utilizado en los servicios religiosos. En cuanto a los hablantes de esta lengua, denominados raizales, de un total de 18971, el $79.52 \%$ afirma hablar la lengua, mientras que el $20.37 \%$ afirma no hablarla, el porcentaje restante afirma hablar otra lengua (Moya 2010b). Por último, es importante resaltar que hay un aumento del monolingüismo en castellano, el bilingüismo más característico es el creole-castellano, y la lengua criolla es vista como una barrera educativa, y no como un elemento que potencie avances sociales en la isla (Sanmiguel 2007).

En definitiva, Colombia es un país de una gran diversidad lingüística. En él no solo conviven diversas variedades dialectales del castellano, sino que, además, múltiples lenguas indígenas y criollas están en contacto entre sí y con la lengua mayoritaria. Esto ha generado diversos procesos de bilingüismo y trilingüismo. A continuación se presentan las políticas lingüísticas que se han encargado de regular dicha diversidad.

\section{POLÍTICAS LINGÜÍSTICAS EN EL ÁMBITO COLOMBIANO}

Las políticas lingüísticas colombianas pueden ser clasificadas en dos grandes grupos, en consideración a los objetivos que se proponen: (1) políticas que buscan regular la relación entre el castellano y las lenguas minoritarias, y (2) aquellas que proponen la implementación de un idioma extranjero. En este apartado, se presenta un breve recorrido histórico de cada uno de estos grupos. El propósito de dicho recuento es contextualizar al lector sobre la forma en que se normativiza la diversidad lingüística en el país, para luego analizar las tensiones y conflictos que han generado dichas políticas en las lenguas colombianas, específicamente aquellas que promueven el aprendizaje de una lengua mayoritaria. En relación con el primer grupo, se puede afirmar que las políticas lingüísticas durante la conquista y la Colonia presentaron dos fenómenos: 
aprender las lenguas indígenas, para poder llevar a cabo los procesos de evangelización a partir de las lenguas nativas, o llevar a cabo un proceso de hispanización que permitiera enseñar «las verdades de la fe a los nativos» a partir del español. Ambas políticas representaban problemas y tuvieron enemigos y adeptos (Ardila 2010:29).

Para alcanzar dicho proceso de evangelización, la corona española implementó la "Política de lenguas generales" (Triana y Antorveza 1987). Esta se basó en el uso de lenguas indígenas, como el muisca, para adoctrinar a las comunidades aborígenes. Con esta norma, dichas lenguas fueron estudiadas y adquirieron cierto estatus.

Una política que cambió radicalmente la relación entre las lenguas aborígenes y el castellano fue la implementación de un programa de castellización implementado por Carlos III. Dicha norma prohibió el uso de las lenguas indígenas con el fin de implementar el castellano como la única lengua de uso social (Gröll 2009). Esto llevó a que se dejaran de estudiar un gran número de lenguas aborígenes y a que sus hablantes tuvieran mayor contacto con el castellano. Por otra parte, en la primera Constitución colombiana, 1886, las lenguas indígenas no son reconocidas, pues se concebía a la nación como una unidad donde se debía implantar una única lengua, una sola religión y un solo gobierno (Gröll 2009). De esta forma, hasta el siglo XIX, las lenguas indígenas y criollas del país no son consideradas como lenguas del Estado.

Un hecho importante en la política lingüística colombiana fue la promulgación de la Constitución de 1991. En esta se da reconocimiento a la diversidad lingüística y cultural del país y, a la par, se reconoce el derecho a la educación bilingüe. A su vez, en el artículo 10 de dicho documento, las lenguas y dialectos de los diferentes grupos étnicos son reconocidos como oficiales en sus territorios. La promulgación de dichas normas llevó a que se empezaran a visibilizar los derechos que las comunidades minoritarias tienen y a pensar en la creación de programas de educación bilingüe, además de un incremento en la investigación de las lenguas aborígenes (Triana y Antorveza 1987). No obstante, los derechos promulgados en la constitución muchas veces no se han hecho realidad debido, por ejemplo, a la falta de herramientas pedagógicas y de inversión por parte del gobierno (Ardila 2010). Para finalizar, cabe resaltar la reciente promulgación de la denominada "ley de lenguas" (Ley No 1381 de enero de 2010). Esta busca fomentar, proteger y preservar las lenguas de los grupos étnicos colombianos al igual que sus culturas, además de hacer más efectiva la participación del Estado en la protección de dichas lenguas. Esta ley se origina debido a la falta real de aplicación de los artículos propuestos en la constitución del año 91. 
En cuanto a las políticas lingüísticas que propenden a la implementación de un idioma extranjero, el recorrido histórico aquí esbozado se basará en las propuestas realizadas por Usma (2009), González (2010) y (Buitrago, García y García 2012). El origen de dichas políticas, a lo largo de la historia colombiana, se da a partir de 1824 con la creación de la cátedra de idiomas en el colegio San Bartolomé en Bogotá, cuyo objetivo era la enseñanza del inglés y el francés como lenguas extranjeras. En 1979, luego de que el presidente francés de esa época visitara Colombia, se originó un decreto que hizo obligatoria la enseñanza del francés en los grados $10^{\circ}$ y $11^{\circ}$ y del inglés para los grados $6^{\circ}$ y $7^{\circ}$. Esto evidencia que hasta ese momento el gobierno colombiano no contaba con una política de lenguas clara, sino que las decisiones acerca de la enseñanza de lenguas extranjeras eran producto de presiones políticas (de Mejia y Montes 2011).

Por otra parte, en 1982, se crea la política denominada The English Syllabus. Ésta fue propuesta por el ministerio nacional de educación junto con el Consejo Británico y el Centro Colombo Americano ${ }^{1}$, buscando introducir un currículo en inglés para los grados $6^{\circ}$ a $11^{\circ}$. Una de las criticas hecha a dicha política fueron los resultados obtenidos; estos no cumplieron las expectativas, dado que los docentes colombianos no se encontraban preparados ni lingüística ni pedagógicamente para asumir dicho reto. Además, había un desajuste entre los objetivos propuestos y las condiciones sociales del país (Usma 2009). La siguiente política lingüística que se implantó en torno a la enseñanza del inglés como lengua extranjera fue el COFE (Colombian Framework for English), a inicios de los 90. Esta política tuvo como objetivo la formación de profesores de inglés en las universidades públicas y privadas del país. Al igual que la política anterior, esta fue suscrita por el Ministerio de Educación en convenio con el Consejo Británico. De nuevo, las críticas a esta política se centraron en los pocos recursos con que contaban las instituciones educativas, la pobre infraestructura de las universidades y la poca formación en investigación por parte de los docentes.

Posteriormente, la "Ley General de Educación" (1994) generó un cambio importante en el sistema educativo colombiano. En relación con las lenguas, se incluyó la necesidad de aprender una lengua extranjera desde la educación básica primaria, al igual que se promulgó un tipo de educación especial para los grupos minoritarios bajo el nombre de "Etnoeducación".

Estas instituciones son organismos binacionales de carácter educativo cultural y comercial, cuyo objetivo central es la promoción de la lengua inglesa y la cultura británica y americana. Han estado presentes en Colombia por varios años, especialmente, después de la segunda guerra mundial. 
Además, se afirmó que la educación para dichas comunidades debía ser bilingüe, respetando su lengua materna. De dicha ley general surgieron los lineamientos curriculares en lenguas extranjeras que buscaron poner en práctica lo promulgado en la "Ley General de Educación", dando origen a los estándares básicos de competencias en lenguas extranjeras, en los que se establecen las habilidades mínimas que debe desarrollar un estudiante de educación básica y media al aprender inglés como lengua extranjera. Estas políticas fueron criticadas debido a que se consideraba que el sistema educativo no se encontraba preparado para asumir el reto de enseñanza de lenguas extranjeras, $y$, además, porque vulneraban la autonomía de las instituciones educativas (Usma 2009).

Más recientemente se originó el "Programa Nacional de Bilingüismo" (PNB), una ley de gran envergadura (2004) cuyo propósito fue mejorar las competencias comunicativas en inglés en todos los niveles educativos hasta lograr que los ciudadanos colombianos sean bilingües en castellanoinglés para el 2019. Dicha política, nuevamente, se originó con el apoyo de entidades internacionales como el Consejo Británico y con la cooperación de compañías transnacionales privadas, como Cambridge University Press. Dichas instituciones fueron las encargadas de hacer el diagnostico frente al nivel de competencia en lengua inglesa de los profesores del país y, junto con el ministerio, propusieron el plan de mejoramiento basados en dicho diagnóstico. Además, fue tan grande el auge de dicha política que a nivel local surgieron ecos de la misma, como lo fue el "Programa Bogotá Bilingüe" (2006), cuyo objetivo era contribuir a que Bogotá y el país se insertaran en la economía global por medio del aprendizaje de una lengua extranjera, el inglés.

Para finalizar este apartado es importante considerar que no es sino hasta la Constitución de 1991 que las lenguas minoritarias adquieren su estado de cooficialidad, ganando algo de prestigio. Esto contrasta con las políticas de enseñanza de lenguas mayoritarias, pues mucho antes de la constitución del 91 hubo un gran interés por implementar una lengua extranjera, en la mayoría de los casos, el inglés. Estas diferencias entre las políticas para lenguas mayoritarias y lenguas minoritarias originan una serie de tensiones que serán descritas en el siguiente apartado. 


\section{TENSIONES ENTRE LAS POLÍTICAS LINGÜÍSTICAS PARA LENGUAS MINORITARIAS Y LENGUAS MAYORITARIAS}

En primer lugar, consideramos que existe una contradicción en las políticas lingüísticas colombianas, específicamente entre el PNB y la Constitución de 1991, junto con su sucesora, la "Ley de lenguas". Dicha contradicción se basa en la forma como se concibe el término bilingüismo en la primera ley. Primero, es necesario entender que el bilingüismo es un fenómeno social e individual (Hamers y Blanc 2000), lo que significa que, además de involucrar el uso de dos códigos por parte de un individuo, es necesario que las lenguas involucradas tengan un uso real en la sociedad, es decir, que tengan vigencia social. En el PNB, el término bilingüismo se limita al nivel de competencia que puede alcanzar un aprendiz colombiano de la lengua extranjera allí propuesta, abandonando el ámbito social. Para Patiño (2005), esto conduce a que los programas educativos en inglés producto del PNB no puedan ser denominados bilingües:

La situación aquí es la de niños y jóvenes que son hablantes de la lengua mayoritaria y a quienes se les enseña intensivamente una lengua extranjera -por lo general el inglés- que es también el vehículo total o parcial de la instrucción general. Pero esta lengua extranjera no tiene una base social en el país; es decir, no es el idioma de una parte de la sociedad colombiana [...]. La ubicación correcta de esa instrucción es el sector pedagógico de la Enseñanza de Segundas Lenguas antes que la pregonada educación bilingüe (Patiño 2005).

Este hecho contrasta fuertemente con el uso del mismo término en la Constitución de 1991 y en la "Ley de lenguas." El reconocimiento co-oficial de las lenguas indígenas y criollas muestra que, evidentemente, dichas lenguas tienen un nicho social en el territorio colombiano. El contacto constante con el castellano permite hablar de bilingüismo, tanto social como individual, pues las comunidades raizales e indígenas en su mayoría adquieren, además de su lengua nativa, la lengua mayoritaria. Hay un uso constante de ambos códigos en contextos reales, ya que hacen parte de la vida diaria de sus hablantes. Esto último no sucede con el inglés, pues aunque es considerada una lengua global, no está inserto en la vida cotidiana de los colombianos ${ }^{2}$. De este modo, un programa que se denomina nacional

\footnotetext{
2 De acuerdo con de Mejía y Montes (2011), la única forma de que el inglés tenga un contexto natural en Colombia podría darse como
} 
debería tener en cuenta los reales fenómenos de bilingüismo existentes en el país. A la par, es necesario que las políticas sean unificadas, es decir, su elaboración debe partir de una base común en relación con los términos a través de los cuales se concibe el bilingüismo.

Además, es importante resaltar que no es posible hablar de bilingüismo en el país como un fenómeno generalizado. Aunque el PNB busca expandir el uso del inglés a nivel nacional, el hecho de que la mayoría de la educación colombiana se haga a través del castellano, hace imposible que el inglés se posicione en al ámbito nacional:

Except for a few exceptions -pilots experiences of bilingual intercultural education in Indian regions and some foreign schools in the main cities in the country-primary and secondary education in Colombia has developed based on Spanish [...] as the first language of $93 \%$ of the Colombian population. Therefore, it is not possible to talk about bilingualism in Colombia as a generalized issue (Iriarte 1997: 23).

Para evitar que las políticas lingüísticas del país se contradigan y generen confusión en torno a lo que es el bilingüismo, es necesario diferenciar entre aquellas políticas como el PNB y las encargadas de regular fenómenos reales de contacto lingüístico. Por ello, y siguiendo a Patiño (2005), proponemos que el PNB sea asumido como un plan de enseñanza de inglés como lengua extranjera, dejando el termino bilingüismo a la situación de lenguas minoritarias, como lo contempla la Constitución y la "Ley de lenguas". Esto, no obstante, involucraría reformular el uso de términos como educación bilingüe, que se ha venido usando mayoritariamente para referirse a programas que involucran la enseñanza de una lengua mayoritaria extranjera (de Mejía 2005). Este término no es usado para referirse a los programas que involucran lenguas minoritarias, pues estos últimos se han denominado "Programas de Etnoeducación". Este hecho, de nuevo, hace que no se reconozcan de igual forma las lenguas minoritarias dentro del ámbito educativo. Se sigue perpetuando la idea de que ser bilingüe en Colombia es hablar castellano e inglés, desconociendo el hecho de que hay individuos bilingües hablantes de castellano y una lengua minoritaria, o hablantes de dos lenguas aborígenes. Siguiendo a Usma (2009), nos sumamos a otros

(...) consecuencia de cambios extendidos en el sistema educativo junto con una progresiva colonización e integración del país a la esfera política de los Estados Unidos, de manera análoga a lo que ocurrió durante la conquista y colonización de América por parte de los españoles; lo que puede percibirse como un peligro a la identidad nacional fundada históricamente sobre la tradición hispánica dominante y fuertemente arraigada (68). 
investigadores que consideran que el limitado uso que se hace del término bilingüismo en el PNB puede traer efectos negativos hacia los diferentes grupos étnicos que componen el país. Para concluir, es importante mirar la preocupación y propuesta que plantea de Mejía (2006):

Restricting the notion of 'bilingualism' to Spanish/English bilingualism leads to a distorted view of the complex interrelationships between languages, cultures and identities in the Colombian context $[\ldots]$ It is equally important that both teachers and school administrators ${ }^{3}$ understand the principles of bilingualism and bilingual education, so that they are able to make informed choices about academic and linguistic issues in their specific bilingual contexts (165).

En segundo lugar, consideramos que el PNB genera, siguiendo a Usma (2009), un fenómeno de estratificación lingüística que se opone al reconocimiento igualitario que la constitución asignó a las lenguas minoritarias. Esto sucede debido a que en el PNB, el inglés es presentado como una lengua con valor instrumental en el mercado laboral, y como único medio para incorporar al país en los procesos de comunicación universal y en la economía global:

El Programa Nacional de Bilingüismo se orienta a "lograr ciudadanos y ciudadanas capaces de comunicarse en inglés, de tal forma que puedan insertar al país en los procesos de comunicación universal, en la economía global y en la apertura cultural, con estándares internacionalmente comparables". Este propósito implica un plan estructurado de desarrollo de las competencias comunicativas a lo largo del sistema educativo (Ministerio de Educación Nacional 2006: 3).

De esta manera, el PNB asume que el inglés provee mejores posibilidades de empleo y trabajo asignándole mayor estatus a esta lengua. Por omisión, las lenguas que no se incluyen en dicho programa, como las lenguas indígenas y criollas, e, incluso, lenguas mayoritarias como el francés, el alemán y el castellano, entre otras, son devaluadas, pues parecería que estas no cumplen dichas finalidades. Del mismo modo, Phillipson (1993) utiliza el término inglés linguicism para referirse a la discriminación sobre la base de las diferencias lingüísticas, según el cual hay lenguas más desarrolladas o más aptas para la vida moderna que otras. Así, calificaciones tales como "lengua internacional" o "mundial", "lengua de comunicación" o "lengua de ciencia", dadas al inglés en el PNB, tienen como reverso la caracterización de las

3 Al igual que los gobernantes que plantean las políticas lingüísticas del país. 
demás como "lenguas locales", "lenguas tribales", "lenguas regionales", "dialectos", "lenguas de exclusión", "lenguas nacionalistas", "lenguas de incultura", "lenguas de pobreza", "lenguas de incomunicación", etc. (Buitrago et al. 2012). Estas implicaciones manifiestan una discriminación lingüística, porque todas las lenguas del mundo son de comunicación, de cultura, de entendimiento, de sabiduría y de excelencia. Si unas tienen más ventajas o extensión que otras, ello se debe a circunstancias ajenas a ellas, tales como los condicionamientos sociales, políticos o económicos que hacen que unas comunidades se vean más favorecidas que otras en uno o varios ámbitos (Phillipson 1993).

El PNB, al denominarse como nacional, y al utilizar una noción específica de bilingüismo, contribuye a la estratificación y subvaloración de las demás lenguas y culturas del país. Este hecho genera la promoción de un "bilingüismo elitista" (de Mejía 2004), es decir, un bilingüismo para un grupo privilegiado de personas que cuentan con los recursos para adquirir la lengua de prestigio, en oposición a los grupos minoritarios. Además, a este grupo, según Bourdieu (1991), pertenecen las personas que tienen la capacidad de mantener y transformar el capital cultural social y económico de una sociedad. Dicha estratificación también se ve reflejada en los modelos de educación propuestos para las comunidades minoritarias y mayoritarias, por lo que pareciera ser que en el país existen dos tipos de educación bilingüe altamente diferenciados o estratificados. El primer grupo, según de Mejía y Montes (2011), se caracteriza por el aprendizaje de lenguas internacionales, mayoritariamente el inglés ${ }^{4}$, por parte de familias de estratos sociales medios y altos que en algunas ocasiones pertenecen a organizaciones multinacionales. En contraste, el otro tipo de educación bilingüe, la etnoeducación, es dada a comunidades rurales que han sufrido la exclusión, la marginalidad y el conflicto armado. En pocas palabras, existe una contradicción clara entre el PNB y la Constitución, generando dos tipos de bilingüismo, uno visible y otro invisible:

Mientras que en Colombia el bilingüismo en lenguas internacionales se considera prestigioso puesto que da acceso a una forma altamente "visible" y socialmente valorada, que abre posibilidades de empleo en

4 Es importante resaltar que para diferentes autores (Guerrero 2008 y Buitrago et al. 2012) el PNB, los lineamientos curriculares en lenguas extranjeras y los estándares básicos de competencias en lenguas extranjeras tienen un concepto limitado y reduccionista de las lenguas extranjeras, pues en realidad se limitan a promocionar el inglés, dejando de lado lenguas con tradición en el país como el francés y el alemán. Así, para estos autores, el término bilingüismo en dichos documentos significa únicamente hablar inglés. 
el mercado global, el bilingüismo en lenguas amerindias o criollas lleva, más bien a una forma "invisible" del bilingüismo en el cual la lengua nativa es subvalorada y asociada con el subdesarrollo, la pobreza y el atraso (de Mejia y Montes 2011: 59).

Para finalizar este punto, es importante resaltar que el PNB entiende las lenguas desde un punto de vista utilitario, dejando de lado los aspectos cognitivos y culturales que estas implican (Usma 2009). Sin embargo, la "Ley de lenguas" reconoce y busca proteger los valores culturales y conocimientos ancestrales que se ven reflejados en las lenguas aborígenes. Esta oposición conduce, a nuestro parecer, a dividir las lenguas del país en dos grupos: uno, donde las lenguas mayoritarias son vistas como lenguas de progreso, y otro, donde se encuentran las lenguas minoritarias vistas como lenguas de cultura, muchas veces folclorizadas. De esta manera, el PNB debería tener en cuenta no solo los posibles beneficios económicos que trae aprender lenguas extranjeras, sino también incluir a las lenguas minoritarias, entendiendo que estas también son lenguas de progreso para Colombia, además de ser el reflejo de la diversidad cultural de la nación.

Una tercera tensión que encontramos en las políticas lingüísticas del país tiene que ver con la mercantilización de la enseñanza de lenguas. Como vimos a lo largo de la historia, las políticas para lenguas extranjeras siempre han sido planteadas con apoyo de entes binacionales, como el Consejo Británico y el centro Colombo Americano ${ }^{5}$. En cambio, las políticas para lenguas minoritarias no han contado con la participación de entes internacionales que conozcan la situación de dichas lenguas y que puedan aportar a solucionar la difícil situación sociolingüística del país. Muchas de las comunidades minoritarias han sufrido una falta de compromiso por parte del gobierno para poner en práctica la constitución y la ley de lenguas. Así, para de Mejía (2005), aunque los programas etnoeducativos son promocionados oficialmente, los recursos asignados a estos no permiten su puesta en marcha.

Por otra parte, la mayoría de los programas de etnoeducación se desarrollan en escuelas públicas, y dependen de secretarías departamentales y municipales, al igual que del Ministerio de Educación; hecho que genera

\footnotetext{
5 Es importante mencionar que autores como Usma (2009) consideran que la cooperación internacional de estas instituciones ha llevado a la mercantilización de las lenguas extranjeras, pues programas como el PNB abrieron un amplio mercado para que dichas instituciones promocionaran sus materiales didácticos, exámenes internacionales, etc. Sin embargo, a dicho mercado solo puede acceder una minoría de los colombianos, pues sus precios son bastante altos, limitando el acceso al inglés a una elite nacional.
} 
burocratización de los recursos. Por su parte, la educación bilingüe en contextos mayoritarios se da, en su mayoría, en colegios privados de familias de clase media alta y con el apoyo de organizaciones extranjeras (de Mejía 2007), lo que conduce a una marcada estratificación. Además, autores como Guerrero (2010) afirman que las políticas lingüísticas, en tanto estándares básicos “... suggests that Spanish, indigenous languages, and English all receive the same budget and investment, but the reality is that the majority of the resources are being used for the spread of English" (Guerrero 2010: 37). A esta postura se suman de Mejía y Montes (2011), al afirmar que: "el contexto de la educación para minorías étnicas y lingüísticas es muy problemático y su financiación poco factible, en claro contraste con lo que ocurre con el contexto de la educación para el bilingüismo de élite al que tiene acceso real una mínima parte de la población (de Mejía y Montes 2011: 71).

La afirmación anterior, específicamente que el acceso a la educación bilingüe inglés-castellano es solo para un grupo reducido de la población colombiana, nos hace cuestionar la inversión que se ha hecho para implantar el PNB. Consideramos que es necesario reevaluar la asignación de recursos dados los resultados que se han obtenido. Por ejemplo, el desempeño de los estudiantes en el área de idiomas de la prueba "Saber 11", entre los años 2007 y 2010 , evidencia que entre el $50 \%$ y el $60 \%$ de los estudiantes que van a finalizar sus estudios secundarios no alcanza un nivel principiante, mientras que sólo entre el $1 \%$ y $2 \%$ de dicha población supera el nivel preintermedio, como se evidencia en la siguiente tabla.

Cuadro 1: Puntaje cualitativo asignado por el ICFES

(Área de idiomas, Prueba Saber 11) (Número de estudiantes)

\begin{tabular}{lrrrr}
\hline \multirow{2}{*}{ Nivel } & \multicolumn{4}{c}{ Año } \\
\cline { 2 - 5 } & \multicolumn{1}{c}{2007} & \multicolumn{1}{c}{2008} & \multicolumn{1}{c}{2009} & \multicolumn{1}{c}{2010} \\
\hline No alcanza el nivel principiante & 239.073 & 307.168 & 290.268 & 324.684 \\
Principiante & 141.598 & 142.275 & 179.546 & 175.386 \\
Básico & 30.141 & 32.463 & 30.898 & 36.467 \\
Pre-intermedio & 19.245 & 18.429 & 23.307 & 23.585 \\
Supera el nivel pre-intermedio & 4.325 & 5.210 & 5.472 & 10.719 \\
\hline Total & $\mathbf{4 3 4 . 6 2 5}$ & $\mathbf{5 0 5 . 5 4 5}$ & $\mathbf{5 2 9 . 4 9 1}$ & $\mathbf{5 7 0 . 8 4 1}$ \\
\hline
\end{tabular}

Fuente: Cálculos del autor con base en información del ICFES

Tomado de Sánchez (2012: 5) 
De esta manera, cuestionamos los alcances y la inversión de recursos de programas que se desprenden de políticas lingüísticas como el PNB, pues estos programas siguen manteniendo una brecha entre la educación privada y pública. Cabe mencionar que es a esta última a la que tienen acceso las comunidades de lenguas minoritarias. A la par, es evidente que la implantación del inglés no solo no ha llevado a altos desempeños en dicha lengua, sino que, además, ha beneficiado a una elite, como lo afirma Sánchez:

Es imperativo que se trabaje en cerrar la brecha, en el nivel de inglés, entre los estudiantes de colegios oficiales y no oficiales, ya que los resultados sugieren que los primeros, quienes representan la mayoría de los bachilleres colombianos, alcanzan un nivel de inglés significativamente bajo, mientras que los segundos continúan alcanzando puntajes comparativamente altos. Los estudiantes bilingües de Colombia representan una proporción muy reducida del total. Se caracterizan, además de su desempeño excepcional en la prueba de idiomas, por ser estudiantes que poseen condiciones socioeconómicas favorables (2012: 37).

En definitiva, las políticas del PNB, especialmente en sus lineamientos, crean lo que Phillipson (1993) denomina un "discurso profesionalista", en tanto consideran el lenguaje y la educación desde una perspectiva estrecha, que excluye aspectos económicos y sociales importantes para su implementación. Este hecho se contrapone con la búsqueda de una reivindicación social de las comunidades minoritarias y sus lenguas, señalada en otros documentos oficiales, como la "Ley de lenguas" y la Constitución. Implementar la enseñanza de una lengua extranjera en el país debe ir de la mano de una serie de medidas que mejoren aspectos tales como el acceso a los materiales educativos, la formación docente y la inclusión social. Dichas políticas no pueden beneficiar solamente a un grupo reducido, mucho menos si se promulgan como políticas de carácter nacional.

Una última tensión que es importante mencionar tiene que ver con la desconexión existente entre los tipos de educación que surgen a raíz de las políticas lingüísticas. La denominada "educación bilingüe" del PNB ha tenido un vasto desarrollo a nivel económico y discursivo, lo que se ha traducido en que el Ministerio de Educación se ha encargado de establecer estándares, lineamientos, evaluaciones y metas en el tiempo en relación con la implementación del ingles en el país. En contraste, la educación para lenguas minoritarias no cuenta con dichos atributos, y el Gobierno no ha establecido cuáles son las metas a alcanzar para los próximos años. Además, no hay lineamientos ni estándares con los que se puedan guiar los maestros de estas comunidades, ni con los que se pueda evaluar la calidad 
de la educación intercultural bilingüe. Por consiguiente, se puede percibir que las políticas lingüísticas para comunidades minoritarias tienen un valor discursivo más que pragmático, es decir, las políticas se quedan en su enunciación sin llevar a cabo verdaderos procesos de planeación lingüística que cambien la situación de lenguas minoritarias del país.

Dicha desconexión también se hace evidente en la producción académica colombiana. Consideramos que es relevante que los avances hechos por los investigadores en ambos modelos de educación empiecen a entrar en diálogo. Esto enriquecería las formas de entender los fenómenos de bilingüismo del país y ayudaría, sobre todo, a clarificar la terminología usada, pues, como se ha evidenciado a lo largo del texto, términos como "educación bilingüe" y "bilingüismo" son utilizados desde perspectivas diferentes. Por lo tanto, nos sumamos a la propuesta planteada por de Mejía (2005), que busca una perspectiva integrada de la educación bilingüe en Colombia:

[...] it can be seen that as bilingual education programs for majority and minority language speakers are concerned with language and cultural contact at regional, national, or international level, it is important to develop positive attitudes towards difference and diversity among those involved in this programs. Increased contact and opportunities for sharing the results of research projects and pedagogical initiatives may help to avoid the danger of fragmentation and compartmentalization which have characterized the development of bilingualism both in ethnic communities and in elite bilingual schools, and lead to greater understanding of common points of interests (62).

\section{EL CASO DEL CRIOLLO SANANDRESANO: EJEMPLO DE LAS TENSIONES GENERADAS POR LAS POLÍTICAS LINGÜÍSTICAS COLOMBIANAS}

En este apartado pondremos en práctica algunas de las tensiones antes descritas por medio de una mirada al caso de San Andrés, Providencia y Santa Catalina. Presentamos, en primer lugar, una breve caracterización del contacto de lenguas en las islas para contextualizar al lector; luego, se realizará el análisis propuesto. Cabe mencionar que dicho análisis es una reflexión preliminar que requiere mayores investigaciones al respecto.

Las islas de San Andrés, Providencia y Santa Catalina se encuentran ubicadas en el en el Mar Caribe a 489 kilómetros de la costa continental colombiana. En ellas conviven tres lenguas: el inglés criollo, el castellano 
y el inglés caribeño. El primero es la lengua materna de un grupo étnico denominado raizal, el que se estableció a principios del siglo XVII en la isla debido a las migraciones provenientes de Jamaica. El castellano es la lengua dominante en el territorio, debido al proceso de hispanización que sufrió la isla durante varios años, pero especialmente con la declaración como puerto libre en 1953 (Sanmiguel 2007). Esta declaración atrajo a una gran cantidad de colombianos continentales hablantes de castellano, convirtiendo a la comunidad raizal en minoría lingüística y demográfica. Una distinción importante entre San Andrés y las demás islas, Providencia y Santa Catalina, es que en estas el uso del criollo y del estándar local es mayoritario, pues el proceso de hispanización no ha sido tan importante (Dittmann 1992). Además, en estas dos islas, la lengua criolla es la lengua materna y mayoritaria. Por su parte, el inglés estándar es una lengua de uso bastante restringido en todas las islas, pues se limita a actividades como la lectura de textos bíblicos y a la transmisión de mensajes religiosos (Abouchaar 2002).

En cuanto a los roles sociales de las lenguas, el castellano y el criollo tiene funciones especializadas. El castellano se usa en contextos formalizados y el criollo en ámbitos cotidianos e informales. En el estudio realizado por Abouchaar (2002), en Providencia y Santa Catalina, se concluye que la lengua criolla es hablada a los niños, convirtiéndola en la lengua materna de la mayoria de la población de estas dos islas. También dicho estudio afirma que en la escuela los contenidos se presentan en castellano, aunque en algunas oportunidades, y especialmente en los primeros grados, la lengua criolla es usada de manera oral para realizar las explicaciones. Es importante resaltar que en San Andrés el uso del criollo ha sido marginado y posee baja presencia en los medios de comunicación (Sanmiguel 2007). Finalmente, es importante mencionar que la Constitución de 1991 dio estatus de cooficialidad a la lengua criolla y abrió un campo para la reivindicacion del grupo raizal, tanto a nivel lingüístico como cultural.

Como mencionamos en el apartado de las tensiones, las políticas lingüísticas del país han desconocido la diversidad lingüística del mismo y centrado sus esfuerzos en la implementación del inglés. En el caso de San Andrés, las propuestas de educación bilingüe casi siempre se han enfocado en el desarrollo del inglés y el castellano. Ejemplo de ello son las acciones que se adelantaron en la oficina de etnoeducación, con el apoyo del Ministerio, que buscaba mejorar las competencias en inglés y castellano de los docentes y estudiantes de la región (Moya 2010a) . Además, el Ministerio propuso, a inicios de los 80 , introducir el bilingüismo castellano-inglés desde el primer grado de básica primaria. Más adelante, y en convenio con la Universidad Pedagógica y Tecnológica, se propuso un programa de educación bilingüe en 
donde los isleños y los continentales serian separados, dadas sus condiciones lingüísticas. A los primeros se les daría una educación en inglés, mientras que a los últimos en castellano (Abouchaar 2002).

Por otra parte, un hecho relevante fue la creación del proyecto denominado Desarrollo de la Educación Bilingüe para el Nivel de Básica Primaria en la Intendencia Especial de San Andrés y Providencia. Este proyecto, llevado a cabo por el Consejo Británico, el Instituto Electrónico de Idiomas y el Ministerio de Educación, buscaba que la educación primaria fuera en un $60 \%$ en castellano y en un $40 \%$ en inglés (Abouchaar 2002). Otra política educativa en la isla fue la implementación de un programa de educación bilingüe en 1991 por parte de la oficina de bilingüismo en el municipio de Providencia. El objetivo de este programa era lograr que los estudiantes de diez escuelas fueran capaces de utilizar el castellano y el inglés de manera eficaz (Abouchaar 2002). Incluso, luego de la promulgación de la Constitución de 1991, la Secretaria de Educación y la Oficina de Educación y Etnodesarrollo del Departamento promulgan el Proyecto Decenal de Bilingüismo y Educación Bilingüe para el Departamento de San Andrés y Providencia, en 1995. En este proyecto, aunque se reconoce la importancia que juega la lengua materna en los procesos de alfabetización, no se distingue claramente entre inglés y lengua criolla, y ambas denominaciones se usan indistintamente para referirse al mismo código (Abouchaar 2002).

Este recuento de las políticas lingüísticas implementadas en el archipiélago evidencia la manera como el discurso oficial deslegitima la existencia del criollo en las islas, favoreciendo la hegemonía del inglés. De nuevo, el concepto de bilingüismo utilizado en los documentos oficiales es reduccionista, pues no comprende el "bilingüismo social" presente en esta región. Dichas políticas van de la mano con el PNB, pues este documento también desconoce la situación de trilingüismo presente en las islas, al concebir el bilingüismo a nivel nacional como el manejo de dos lenguas mayoritarias, el inglés y el castellano. Por consiguiente, las contradicciones planteadas en las políticas lingüísticas del país, la constitución y el PNB entre otras, afectan los programas educativos propuestos para minorías lingüísticas, tal como se evidencia en el caso de la comunidad raizal hablante de criollo.

En cuanto a la estratificación lingüística, las políticas educativas hasta aquí expuestas muestran que el inglés debe ser la lengua de la educación. Esto significa que, por omisión, el criollo no es una lengua apta para llevar a cabo procesos de escolarización. Esta distinción mantiene la idea, largamente sostenida, de que las lenguas criollas no son vehículo de conocimiento debido a sus supuestas limitaciones lingüísticas y, por consiguiente, deben limitarse a ámbitos reducidos como el hogar, como afirma Migge (2010): 
Many decision makers, as well as the population at large, do not see pidgins and creoles as legitimate tools of education, bud perceive them as corrupt derivatives of the standard language that lack a clearly defined grammar. This perception was particularly strong in situations in which the pidgin and Creole exist in a sociolinguistic continuum with its related European language (11).

Este hecho se ve reflejado aún en las políticas educativas propuestas para el archipiélago, pues estas, durante mucho tiempo, solo consideraron al inglés como lengua legitima de ser implantada en la educación, incluso cuando su uso a nivel social es reducido, como lo demuestran los estudios sociolingüísticos (Abouchaar 2002). A esta idea se suma el hecho de que algunos miembros de la Secretaria de Educación mantienen el discurso propuesto por el PNB, en donde se concibe al inglés como la única lengua de progreso, con beneficios económicos y sociales. En contraste, el criollo es concebido como una lengua "limitada", y no "formal"; por ello no brinda los mismos beneficios que el inglés. En palabras de un miembro de la secretaria de educación del archipiélago:

What can people communicate in Creole? Creole languages are limited in vocabulary, semantics, in communicating ideas. Creole speakers have a disadvantage. Get rid of that, have more equity in communication. Native people can't have a job outside like Grand Cayman. In English they communicate better when being outside [...] English is a huge business [...] instead of Creole. If we keep Creole, we are in trouble. English has always been there. [...] we want to have a bilingual system English L1, Spanish. I don't see Creole in an important role. I don't think it should have an important role. It is not easy to have both Creole and English (Moya 2010b: 68).

Como se evidencia, una parte del discurso oficial se opone a las políticas lingüísticas, como la Constitución y la "Ley de lenguas", que reivindican el uso de la lengua materna en la educación, en este caso, el criollo de base léxica inglesa. Consideramos que el discurso propuesto en el PNB ha generado una serie de representaciones erróneas sobre lo que significa ser bilingüe en el país. El carácter nacional de esta política y su constante divulgación han generado ciertos efectos en la forma como la población en general concibe el bilingüismo y sus beneficios.

Una forma de evidenciar la mercantilización de las lenguas es a través del estudio de las pocas propuestas educativas que incluyen el criollo como lengua de instrucción para el archipiélago de San Andrés y Providencia. Una de estas propuestas fue el proyecto piloto trilingüe de la Universidad 
Cristiana de San Andrés (Bowie y Dittman 2007 y Morren 2001), cuyo objetivo era implementar un currículo en inglés criollo, ingles estándar y castellano, del grado primero a quinto, en dos instituciones educativas de la isla. El proyecto proponía iniciar la alfabetización en criollo, para luego hacer una transición al inglés en segundo y tercer grado de primaria y, finalmente, abordar la lecto-escritura en castellano en tercero y cuarto. El programa buscaba que en $5^{\circ}$ grado la distribución de lenguas fuera $50 \%$ inglés y $50 \%$ castellano.

Dichos programas presentaron una serie de dificultades que impidieron su desarrollo y posible implementación. Estos problemas estaban estrechamente ligados con la falta de recursos y apoyo de las autoridades locales. En términos de las autoras de la primera propuesta, el éxito del proyecto se debilitó por "(...) una falta de apoyo real, al menos en la forma de una noobstaculización del proyecto piloto por parte de la secretaria de educación y la oficina de etnoeducación bilingüe [...] y por mejores condiciones físicas y de equipamiento de las escuelas" (Bowie y Dittman 2007: 72). Este hecho evidencia que la asignación de recursos a programas minoritarios es limitada e, incluso, entorpecida, lo que contrasta con los grandes esfuerzos que se han hecho por promover la enseñanza del inglés a nivel nacional a través del PNB (Guerrero 2010). Esto también es resaltado por Morren (2001), quien participó en la consolidación del proyecto. Durante éste, el proceso se vio enteorpecido debido al traslado de algunos docentes participantes a otras instituciones: "The new Secretary of Education initiated a change of some teachers and administrators. This restructuring could have simply been a cost-saving effort or it could have been a means of inhibiting the trilingual education endeavour, as some of the supporters of trilingual education believe" (239).

Sumado a lo anterior, las instituciones participantes en el proyecto piloto sienten que el gobierno nacional obstaculiza el desarrollo de sus iniciativas. Esto los ha llevado a pensar en convertirse en instituciones de carácter privado, pues solo así tendrían la autonomía para implementar verdaderas políticas de bilingüismo en lengua criolla (Morren 2001). Este fenómeno es interesante en la medida en que refleja el concepto de "bilingüismo elitista", propuesto por de Mejía y Montes (Mejía y Montes 2011). Aunque algunas políticas nacionales promueven y defienden la etnoeducación, en la práctica este tipo de educación no cuenta con el apoyo gubernamental, como sí sucede con la implementación del inglés en el país. Es irónico que para hacer etnoeducación en el archipiélago, la educación deba privatizarse. Esto último afianza la idea de que la educación en bilingüismo en el país solo será exitosa si se hace desde la esfera privada, como lo demostró Sánchez (2012) en su estudio sobre el PNB. 


\section{CONCLUSIONES}

Luego de presentar una breve descripción de la situación sociolingüística de Colombia, de la cual se concluye que el país es lingüísticamente diverso, planteamos un recorrido histórico por las políticas lingüísticas más importantes del país, clasificadas en políticas para grupos mayoritarios y políticas para grupos minoritarios. Del análisis de dichas políticas surgieron cuatro tensiones que afectan a las lenguas indígenas y criollas. Dichas tensiones son: (1) existe una contradicción en la forma como se concibe el término "bilingüismo" en la Constitución de 1991, la "Ley de lenguas" y el PNB; (2) el PNB genera un fenómeno de estratificación lingüística que se opone al reconocimiento igualitario que la Constitución asignó a las lenguas minoritarias; (3) la asignación de recursos para la implantación del inglés contrasta con el escaso financiamiento de los Programas de Etnoeducación, generando una mercantilización de la enseñanza de lenguas en el país; (4) existe una desconexión entre los tipos de educación que surgen a raíz de las políticas lingüísticas, es decir, mientras que los programas como el PNB han tenido extensos desarrollos, no sucede lo mismo para Programas de Etnoeducación Bilingüe.

Dichas tensiones se ejemplificaron con el caso del criollo sanandresano. De esta parte, podemos afirmar que la noción limitada del "bilingüismo" en algunas políticas lingüísticas no permite que el criollo sea concebido como una lengua con completa validez para ser implementada en la escuela. Además, la estratificación lingüística originada por el PNB ha mantenido la idea de que las lenguas criollas son deficientes y no contribuyen al desarrollo del país. Por último, se evidenció que la inversión para los Programas de Etnoeducación en San Andrés es limitada y contrasta con los recursos asignados a los programas de educación inglés-castellano.

En definitiva, consideramos que en Colombia no es posible hablar de un Programa Nacional de Bilingüismo, por dos razones: primero, porque el PNB desconoce la diversidad lingüística del país y, en segundo lugar, entra en una serie de contradicciones con otras políticas lingüísticas promulgadas en Colombia. El PNB es más bien una política de promoción del inglés como lengua extranjera. Creemos, junto a de Mejía (2007) que "(...) si Colombia pretende promulgar el bilingüismo como política de estado en un futuro próximo es importante que ésta sea una política inclusiva, que reconozca la larga tradición del país como nación multilingüe y pluricultural" (38). 


\section{REFERENCIAS BIBLIOGRÁFICAS}

AbouchaAr, Alberto. 2002. Estudio lingüístico para la implementación del programa de educación bilingüe en el municipio de Providencia y Santa Catalina. Cuadernos del Caribe 3: 65-101.

Aguirre Licht, Daniel. 2009. Las lenguas autóctonas en Colombia consideraciones alrededor de su legitimación en la Constitución de 1991. Bogotá: Universidad de Los Andes.

Ardila, Olga. 2007. Estudio sociolingüístico del Amazonas. Revista internacional Magisterio 25: 48-51.

2010. Las lenguas indígenas de Colombia: problemáticas y perspectivas. UniverSOS 7: 27-39.

2012. Lenguas indígenas y criollas de Colombia: un balance de su situación actual. Bogotá: Universidad Nacional de Colombia, Instituto Caro y Cuervo..

Bourdieu, Pierre. 1991. Language and symbolic power. Cambridge: Polity.

Bowie, Pauline y Marcia Dittman. 2007. El proyecto piloto trilingüe de la Universidad Cristiana de San Andrés en las escuelas Emanuel Bautista y Bautista Central en la isla de San Andrés. En Anne-Marie de Truscott de Mejía y Sol Colmenares (eds.). Bialfabetismo: lectura y escritura en dos lenguas en Colombia, pp. 67-87. Cali: Universidad del Valle.

Buitrago, Yudi, Javier García y David García. 2012. Imposición lingüística o la fábula del progreso bilingüe en Colombia: reflexiones sobre la enseñanza del inglés. Memorias $V$ Simposio Pedagógico Lenguajes, lectura y escritura. Bogotá: Red de Pedagogía.

DitTman, Marcia. 1992. El criollo sanandresano lengua y cultura. Cali: Universidad del Valle.

GonzÁlez, Adriana. 2010. English and English teaching in Colombia: Tensions and possibilities in the expanding circle. En Andy Kirkpatrick (ed.). The Routlegde Handbook Of World Englishes, pp. 332 - 351. London: Routledge.

González, María. 2010. Las lenguas indígenas de Colombia a vuelo de pájaro UniverSOS 7: 9-25.

GrölL, ILSE. 2009. Las lenguas amerindias y criollas en Colombia. Desarrollos políticos lingüísticos en el marco de la Constitución Política de 1991. En Daniel Aguirre (comp.). Las lenguas autóctonas en Colombia. Consideraciones alrededor de su legitimación en la Constitución de 1991, pp. 13-116. Bogotá: Universidad de Los Andes.

Guerrero, Carmen. 2008. Bilingual Colombia: What does it mean to Be Bilingual within the Framework of the National Plan of Bolinguism. PROFILE 10: 27-45.

2010. The Portrayal of EFL Teach ers in Official Discourse: The Perpetuation of Disdain. PROFILE, 12(2): 33-49.

Hamers, Josiane y Michel Blanc. 2000. Bilinguality and Bilingualism. Cambridge: Cambridge University Press.

IRIARTE, GenoveVA. 1997. Bilingüismo y sociolingüística Bilingüismo, función cogniscitiva y educación. Bogotá: Fondo de publicaciones del Gimnasio Moderno.

de Mejía, Anne-Marie Truscott. 2006. Bilingual Education in Colombia:Towards a Recognition of Languages, Cultures and Identities. Colombian Applied Linguistics Journal 8: 152-168.

de Mejía, Anne-Marie Truscott y Christine Helot. 2008. Points of Contact or Separate paths: A Vision of Bilingual Education in Colombia, pp. 109-139. Bristol: Multilingual Matters.

de Mejía, Anne-Marie Truscott y María Emilia Montes. 2011. El bilingüismo y el multilingüismo en Colombia: Consideraciones acerca de su valor y promulgación. En Elzira Yoko y Juliana Santana (eds.). Bilinguismos: subjetivação e identificações nas/pelas linguas maternas e estrangeiras, pp. 55-81. Campinas: Pontes Editores. 
de Mejía, Anne-Marie Truscott. 2005. Bilingual education in Colombia: Towards an integrated perspective. En Anne-Marie Truscott de Mejia (ed.). Bilingual education and bilingualism, pp. 48-64. Clevedon: Multilingual Matters.

2004. Bilingual education in Colombia: towards an integrative perspective. Bilingual education and bilingualism 7 (4): 381-397.

2007. Visiones del Bilingüismo y de la educación bilingüe en Colombia. Revista Internacional Magisterio 25: 36-38.

Migge, Bettina, Isabelle Léglise y Angela Bartens. 2010. Creoles in Education. A discussion of pertinent issues. En Creoles in Education. An appraisal of current programs and projects, pp. 1-30. Amsterdam: John Benjamins.

Morren, Ronald C. 2001. Creole-based Trilingual Education in the Caribbean Archipelago of San Andres, Providence and Santa Catalina. Journal of Multilingual and Multicultural Development 22 (3): 227-241.

Moya, Sindy. 2010a. La escuela en San Andrés isla. Cuadernos de Bilingüismo 1: 41-54.

2010b. Situación sociolingüistica de la lengua creole de San Andrés isla, el caso de San Luis. (Maestría en Lingüística), Universidad Nacional de Colombia, Bogotá.

Ministerio de Educación Nacional. 2006. Estándares básicos de competencias en lenguas extranjeras:inglés. Formar en lenguas extranjeras: el reto. [en línea]. Disponible en: http://www.colombiaaprende.edu.co/html/mediateca/1607/articles-115375_archivo.pdf. (Consulta: 01/06/12)

Patiño, Carlos. 2005. La enseñanza del español Vigia del idioma. Bogotá: Academia Colombiana de la Lengua.

Phillipson, Robert. 1993. Linguistic Imperialism. Oxford: Oxford University Press.

SANCHÉz, ANDRÉs. 2012. El bilingüismo en los bachilleres colombianos Documentos de trabajo sobre economía regional. Cartagena: Banco de la República.

Sanmiguel, Raquel. 2007. El bilingüismo en el Archipiélago de San Andrés, Providencia y Santa Catalina. Revista Internacional Magisterio 25: 28-31.

Triana y Antorveza, Humberto. 1987. Las lenguas indígenas en la Historia social del Nuevo Reino de Granada. Bogotá: Instituto Caro y Cuervo.

Usma, Jaime. 2009. Education and Language Policy in Colombia:Exploring processes of Inclusion, Exclusion, and Stratification of Global Reform. PROFILE 11: 123-141. 